\title{
Hospice eligibility in patients who died in a tertiary care center
}

\author{
Katherine Freund ${ }^{1}$, Michelle T. Weckmann, MS MD ${ }^{2,3}$, David J Casarett, MD ${ }^{4,5}$, Kristi \\ Swanson ${ }^{2}$, Mary Kay Brooks ${ }^{6}$, and Ann Broderick, MS MD ${ }^{7}$ \\ ${ }^{1}$ University of lowa, Roy and Lucille Carver College of Medicine, lowa City, IA, USA \\ ${ }^{2}$ Department of Family Medicine, University of lowa Carver College of Medicine, lowa City, IA, \\ USA
}

${ }^{3}$ Department of Psychiatry, University of lowa Carver College of Medicine, lowa City, IA, USA

${ }^{4}$ Department of Medicine, University of Pennsylvania, Philadelphia, PA, USA

${ }^{5}$ Institute on Aging, Center for Bioethics, Philadelphia Veterans Affairs Center for Health Equity Research and Promotion, Philadelphia, PA, USA

${ }^{6}$ Office of Clinical Quality, Safety, and Performance Improvement, University of lowa Hospitals and Clinics, lowa City, IA, USA

${ }^{7}$ Department of Internal Medicine, University of lowa Carver College of Medicine, lowa City, IA, USA

\section{Abstract}

Background-Hospice is a service that patients, families and physicians find beneficial, yet a majority of patients die without receiving hospice care. Little is known about how many hospitalized patients are hospice eligible at the time of hospitalization.

Methods-Retrospective chart review was used to examine all adult deaths $(\mathrm{n}=688)$ at a tertiary care center during 2009. Charts were selected for full review if the death was non-traumatic and the patient had a hospital admission (penultimate admission) within 12 months of the terminal admission. The charts were examined for hospice eligibility based on medical criteria, evidence of a hospice discussion and hospice enrollment.

Results-209 patients had an admission in the year preceding the terminal admission and a nontraumatic death. $60 \%$ were hospice eligible during the penultimate admission. Hospice discussions were documented in $14 \%$ of the hospice eligible patients. Patients who were hospice eligible had more subspecialty consults on the penultimate admission compared to those not hospice eligible ( $\mathrm{p}=0.016$ ), as well as more overall hospitalizations in the 12 months preceding their terminal admission $(\mathrm{p}=0.0003)$ and fewer days between their penultimate admission and death $(\mathrm{p}=0.001)$.

Conclusion-The majority of terminally ill inpatients did not have a documented discussion of hospice with their care provider. Educating physicians to recognize the stepwise decline of most

Corresponding Author: Michelle T. Weckmann, MD, University of Iowa, Department of Family Medicine, 01102 PFP, Iowa City, IA 52242-1000. Tel: 319-384-7000. FAX: 319-384-7822. michelle-weckmann@uiowa.edu.

Financial Disclosure Statement: None of the authors have any financial conflicts of interest to report with regards to the content of this manuscript. 
illnesses and hospice admission criteria will facilitate a more informed decision making process for patients and their families. A consistent commitment to offer hospice earlier than the terminal admission would increase access to community or home-based care, potentially increasing quality of life.

\section{Introduction}

Hospice provides a wide range of palliative and supportive services to patients and families facing a life-limiting illness which include specialized medical care, aggressive pain and symptom management and emotional and spiritual support. Hospice has been shown to benefit both patients and families by improving satisfaction and pain management, reducing medical costs and unmet needs and decreasing family member's concerns, ${ }^{1-4}$ yet services are underutilized. In over 25 years of the Medicare hospice benefit, the median length of hospice stay has remained approximately 20-22 days. This is consistent with the National Hospice and Palliative Care Organization (NHPCO) 2009 report which reveals that approximately $41.6 \%$ of all deaths in the United States occurred under the care of a hospice program with more than half of the patients having a length of hospice service less than 21.1 days. The short length of stay is significant since bereaved families commonly report that more time in hospice would have been beneficial. ${ }^{5}$

Medicare has two requirements for hospice eligibility: 1) the patient must understand that his/her illness is life limiting and be willing to forego curative therapy and 2) two physicians must declare that the patient has 6 months or less to live. Hospice agencies often rely on NHPCO published worksheets (designed to identify patients with a prognosis of less than 6 months) to assist in determining if a patient meets the Medicare requirements. Even when a patient might meet Medicare requirements for hospice, many do not receive hospice services prior to their death. Physicians, patients, and families all present different barriers to hospice referrals which include; physician difficulty with accurate prognostication, physician grief and feelings of inadequacy, lack of knowledge about hospice and the referral process, and decreased communication between decision makers. ${ }^{6-89}$ A majority of the barriers to hospice referral may be overcome with education and normalization of hospice as an appropriate and effective medical intervention.

It is not known how often clinicians recognize that a patient is hospice eligible, nor is it known how often discussion of hospice occurs with appropriate patients or families. Studies in nursing homes and among advanced cancer patients demonstrate that physicians do not recognize hospice eligible patients and as a consequence hospice is not mentioned as a treatment option; however, when physicians are informed that a patient is hospice eligible and a hospice informational visit is provided, the physician is more likely to refer and the patient is much more likely to utilize hospice services. ${ }^{7,10,11}$ Earlier access to hospice improves care, helps ensure medically appropriate services are received, helps ensure death occurs in the preferred location, and is preferred by caregivers. ${ }^{12}$ In order to consider hospice, the treating physician needs to recognize and accept that the patient is dying. The goal of this study was to determine the percentage of patients who met guidelines for hospice admission and had a documented discussion regarding hospice appropriateness in 
the medical record during a penultimate admission defined as the hospital admission which preceded death.

\section{Methods}

\section{Study Selection and Population}

This study was approved by the University of Iowa Institutional Review Board. A summer research medical student (KF), who was closely supervised by the principle investigator, reviewed the electronic medical record of all adult inpatient deaths at The University of Iowa Hospitals and Clinics (UIHC) in 2009 (Figure 1). Traumatic deaths were excluded. For each eligible patient, KF recorded age, sex, race and date of death. For those patients who had a hospitalization in the previous 12 months, KF reviewed all physician and social work notes from both the penultimate and terminal admissions and recorded primary and secondary diagnoses from both admissions, hospice enrollment at the time of either admission, evidence of a hospice discussion, occurrence of a palliative care consult during either admission, number of subspecialist referrals during the penultimate admission, length of stay and total hospital costs for each admission.

\section{Hospice Guidelines}

The National Hospice and Palliative Care Organization (NHPCO) has published worksheets for hospice admission that are the standard for determining hospice eligibility based on prognosis. ${ }^{13,14}$ The worksheets do not address the patient's goals of care and acceptance of palliative based treatments. Rather, the worksheets are disease specific and include: cancer, pulmonary disease, heart disease, neurological illness (stroke, ALS, MS, etc), renal disease, HIV, dementia, clinical decline and liver disease. Despite the fact that NHPCO intended these worksheets to be used as guidelines, they are often used by hospice agencies strictly in determining hospice eligibility. We designed our data collection sheet to strictly reflect the worksheet criteria. The penultimate discharge summary was reviewed by KF, and the primary and secondary discharge diagnoses were compared to the NHPCO worksheets. Data needed to support worksheet-based determinations of eligibility were collected (medications, laboratory values, echocardiographic results, pulmonary function test results, radiographic scans and films, vital signs and speech pathology reports). Whenever possible we used objective data (i.e., FEV1 for respiratory criteria) versus subjective reports (i.e., shortness of breath) to make the hospice eligibility determination.

While Medicare guidelines say a patient is eligible for hospice when two physicians believe the patient has a prognosis of 6 months or less, there is no penalty if the patient outlives the physician's prognosis. The patient can continue to receive hospice services as long as the physicians continue to believe the prognosis remains less than 6 months if the disease were to follow the expected trajectory. We elected to evaluate the 12 month time period prior to the terminal admission recognizing that while " 6 months" is the legislative guideline, historically, a substantial number of patients receive hospice services for over 180 days. ${ }^{15,16}$ 


\section{Statistical Analysis}

Data were entered in a database using unique identifiers. Statistical analysis was conducted using SPSS 18 and SAS 9.2 for Windows (SAS 9.2, SAS Institute, Inc., Cary, NC). Standard descriptive statistics were used with a 2 sample t-test to describe differences in age, number of secondary organ systems, and number of subspecialty consults among those who were hospice eligible and those that were ineligible. The Chi Square statistic, as well as the Fisher exact test, was used to test for significant differences in proportions of sex, race, primary diagnosis, days between penultimate and terminal admission, and type of insurance/payer for patients who were hospice eligible versus those that were ineligible. More specifically, the Fisher exact test was used to test proportions that did not meet the criterion for approximation with the chi square test statistic. These proportions included primary diagnosis and type of insurance/payer. McNemar's test for paired data was used to evaluate differences in proportions of documentation of a hospice discussion at the terminal admission versus the penultimate admission, as well as the presence of a palliative care consultation. Corresponding p-values were recorded, with significance being considered at the standard level of 0.05 . SPSS 18 was used to evaluate inter-rater reliability using Cohen's Kappa.

\section{Inter-rater reliability}

The data extraction was conducted by a medical student who was trained in use of the NHPCO worksheets (KF). To insure KF was using the worksheets adequately, all the charts where a determination of not hospice eligible or clinical decline was made were initially reviewed by the PI (MW) until 10 consecutive charts were error free. To insure reliability of the data abstraction, $25 \%$ of the charts were randomly assigned to three other reviewers: $5 \%$ to the study PI, a board certified hospice and palliative medicine physician with 5 years of experience as a hospice medical director (MW), $10 \%$ to a board certified hospice and palliative medicine physician with 10 years of experience as a hospice medical director $(\mathrm{AB})$ and $10 \%$ to a quality control registered nurse without hospice experience (MKB). Disagreements were recorded and resolved by consensus between two reviewers (MW and $\mathrm{AB})$.

\section{Results}

\section{Hospital Characteristics}

This study involved patients who were admitted and died at a large, tertiary care, academic institution. The catchment area is large and includes three states and there are no known "open access" hospice agencies in the area. The hospital has 734 beds and patients are cared for by either a teaching team (residents, learners and attending) or by a physician (hospitalist) working with a physician extender (physician assistant or nurse practitioner). The majority of penultimate admissions (76\%) were to a resident teaching team. More details regarding admitting services and hospice eligibility at the penultimate admission can be seen in Table 1. 


\section{Patient characteristics}

Of the 688 adult patients who died during 2009 at UIHC, 209 (31\%) had both a nontraumatic death and a penultimate admission in the 12 months preceding the terminal admission. Of the 209 who met eligibility criteria for a full chart review, the mean age was 63 , the majority of patients were male, cancer was the most common terminal diagnosis, and $83 \%$ were white, which is reflective of the regional population. There were no significant differences between age, sex, race or insurance coverage between patients who did and did not meet hospice eligibility criteria. The majority of patients (139/208) had one or two hospitalizations in the 12 months prior to their terminal admission (range 1-17) and patients eligible for hospice had more hospitalizations in the 12 months prior to their terminal admission than the patients not eligible for hospice (mean 3.3 versus 1.9, $\mathrm{p}=0.0003$ ). (Table 2) The combined Kappa rating between the primary reviewer (KF) and the other 3 reviewers was 0.754 , indicating a substantial degree of reliability.

\section{Penultimate admission data}

A total of $125 / 209$ or $60 \%$ of the patients met NHPCO guidelines for hospice admission at the time of discharge from the penultimate admission. The majority, 175/209 penultimate admissions (84\%) occurred within 6 months of the terminal admissions, and 103/175 (59\%) of the patients with a penultimate admission within 6 months of the terminal admission met NHPCO prognostic guidelines for hospice eligibility. The patients who met hospice prognostication guidelines had significantly more subspecialty consults on the penultimate admission compared to those not hospice eligible (mean of 0.66 versus 0.25$)(\mathrm{p}=0.003)$. (Table 2) Moreover, hospice eligible patients had significantly fewer days between their penultimate admission and death (mean of 62 days versus 128 days) $(\mathrm{p}=0.001)$.

\section{Hospice and palliative care discussions}

Documentation of a hospice discussion was more common during the terminal admission than the penultimate admission ( $23 \%$ versus $14 \%)(\mathrm{p}<0.001)$. Palliative care consultation was also more common at the terminal admission than the penultimate admission (47\% vs. $5 \%)(\mathrm{p}<0.001)$. Of the 126 patients who were hospice eligible at the penultimate admission, 17 had a documented hospice discussion during their penultimate admission (14\%). A formal hospice referral was provided to $11 / 17(64 \%)$ patients prior to discharge, all of which came from a resident teaching team. Of the seven patients referred to hospice by a physician, five enrolled in hospice (the two who did not cited financial reasons), while only one of the four patients referred by a social worker enrolled in hospice. Cancer was the most common diagnosis in patients who had a documented hospice discussion (73\%) followed by the hospice diagnosis of clinical decline (18\%).

\section{Comment}

Our results indicate that the majority of patients (60\%) who died at our large academic hospital met published medical guidelines for hospice enrollment during an admission in the year prior to their terminal admission, yet very few received the choice to utilize hospice services. While bereaved families uniformly express satisfaction with and appreciation of hospice services, hospice is often not mentioned until the patient is imminently dying, and 
this may be the first time the patient realizes hospice is an option. There are a number of reasons why physicians do not mention hospice earlier and most are related to physician concerns with communication of bad news and prognostication. ${ }^{6,7,17}$ However, patients and families overwhelmingly say that they want to engage in difficult discussions and are more satisfied after their care providers bring up topics related to advanced directives. Patients and families do not find discussions of code status uncomfortable, ${ }^{18}$ and hope is maintained even when patients are given truthful prognostic and treatment information. ${ }^{19}$

Communication of prognosis and hospice eligibility would have been appropriate for the majority of the patients in this study. In general, patients want information about healthcare options. Referrals do not require that a patient has to choose hospice care. In our sub-sample of patients with whom hospice was discussed only $41 \%$ chose hospice care which is lower than previous studies. ${ }^{11}$ Who made the referral appeared to impact the patient's willingness to enroll in hospice, with more patients enrolling when the hospice referral was made by a physician. This will be an important area to explore further since improving referral rates has the potential to increase hospice enrollment rates. This is important since hospice has been shown in numerous studies to decrease costs at the end of life as well as decrease length of stay and intensive care utilization while subsequently increasing the quality and satisfaction of the care received. ${ }^{20-24}$

There are no rigorously controlled studies examining hospice discussions. The majority of studies have been case controlled trials. While the present study revealed that hospice discussions with terminally ill inpatients are rare, there are several limitations of our evaluation. We used a retrospective chart review which introduced an unavoidable selection bias. We were unable to capture patients who were recognized as dying, referred to hospice and did not return to the hospital to die. Nor could we capture patients who had a penultimate admission at another hospital, or had a hospice discussion in another setting and did not return to the hospital to die. Further limitations became apparent as we conducted the study. These limitations, however, do not detract from our findings that hospice discussions were rare when patients died in our hospital. Our findings are based solely chart documentation. Hospice discussions could have occurred which were not recorded. However, since it was rare for patients to receive either a palliative care referral or a referral to hospice, it is likely that such discussions were rare. The study was not designed to examine barriers to hospice enrollment. Therefore, we do not know whether the physician did not recognize that the patient was dying or if the physician recognized the terminal nature of the patient's illness and choose not to discuss it. However, we do know hospice was not mentioned as a treatment option in the majority of patients that were medically appropriate for hospice services.

By selecting patients who died in the hospital from non-traumatic causes we were able to limit our study to patients who had a terminal illness. Physicians and hospice agencies typically use the NHPCO worksheets to determine if a patient meets the medical eligibility criteria for hospice enrollment. This study highlighted the lack of sensitivity in the NHPCO worksheets. Strict application of the NHPCO worksheets failed to identify 84 of the 209 patients (40\%) who had a terminal condition. We found the NHPCO worksheets to be inflexible and incomplete due to the limited number of diagnoses covered. We identified 
patients who we believed were hospice eligible from a medical standpoint but the charts did not have sufficient data to support the strict disease specific criteria in the NHPCO worksheets.

One final limitation was the fact that we only addressed whether a patient was eligible for hospice from a prognostic standpoint. We have no knowledge of patient and caregiver goals (due to a lack of documentation) so we were unable to determine if patient goals of care were congruent with the hospice philosophy. The patients who died at the hospital may have self-selected as patients who desired more aggressive care. While it is ideal to discuss the patient's goals of treatment, hopes for quality of life and the wishes of the family on a regular basis, in reality this discussion is not common place. ${ }^{25}$ These discussions can be difficult and time consuming, particularly in a large tertiary care center, and referral to hospice may be impacted by involvement of multiple subspecialty services who may provide organ specific care without a general overview of the patient's status. ${ }^{26,27}$ In fact, when a patient receives a palliative care consult that focuses on the plan of care coordination and communication (not just symptom management), hospice referrals are increased. ${ }^{28,29}$ This is supported by recent studies which reveal the importance of patient goals and advanced care planning in the timing and effectiveness of hospice referral and patient goals would be important data to obtain in future studies. ${ }^{11,30}$

\section{Future studies}

This study provides data detailing how often physicians miss opportunities to discuss an effective medical intervention, hospice, with appropriate hospitalized patients. The study also shows the feasibility of using the NHPCO worksheets to identify hospice eligible patients during an acute hospitalization. In addition, this study presents important information about the current culture and practice of medicine in regards to dying hospitalized patients. It contains the preliminary data necessary to design a prospective, randomized control trial with a targeted intervention to increase the rate of hospice referrals of eligible inpatients. Coordinating care and knowing when to discuss hospice as a treatment option would assist in aligning medical care with patient and family goals. Appropriately timed hospice discussions and referrals would lead to a decrease in the number of acute hospitalizations, decrease the 30 day hospital re-admission rates, lower health care expenses, and improve comfort while tending to the goals and emotional needs of patients and families at the end of life.

\section{Acknowledgments}

The authors would like to thank John Hyman for his assistance with data analysis. Support for this research was provided by the University of Iowa Carver College of Medicine, Medical Student Summer Research Fellowship Program (NIH 2-T35-HL007485-31).

\section{References}

1. Teno JM, Clarridge BR, Casey V, et al. Family perspectives on end-of-life care at the last place of care. JAMA. 2004 Jan 7; 291(1):88-93. [PubMed: 14709580]

2. Miller SC, Mor V, Teno J. Hospice enrollment and pain assessment and management in nursing homes. J Pain Symptom Manage. 2003 Sep; 26(3):791-799. [PubMed: 12967728] 
3. Miller SC, Mor V, Wu N, Gozalo P, Lapane K. Does receipt of hospice care in nursing homes improve the management of pain at the end of life? J Am Geriatr Soc. 2002 Mar; 50(3):507-515. [PubMed: 11943048]

4. Brumley R, Enguidanos S, Jamison P, et al. Increased satisfaction with care and lower costs: results of a randomized trial of in-home palliative care. J AM Geriatr Soc. 2007 Jul; 55(7):993-1000. [PubMed: 17608870]

5. Rickerson E, Harrold J, Kapo J, Carroll JT, Casarett D. Timing of hospice referral and families' perceptions of services: are earlier hospice referrals better? J AM Geriatr Soc. 2005 May; 53(5): 819-823. [PubMed: 15877557]

6. McGorty EK, Bornstein BH. Barriers to physicians' decisions to discuss hospice: insights gained from the United States hospice model. J Eval Clin Pract. 2003 Aug; 9(3):363-372. [PubMed: 12895158]

7. Keating NL, Landrum MB, Rogers SO Jr, et al. Physician factors associated with discussions about end-of-life care. Cancer. 2010 Feb 15; 116(4):998-1006. [PubMed: 20066693]

8. Travis SS, Bernard M, Dixon S, McAuley WJ, Loving G, McClanahan L. Obstacles to palliation and end-of-life care in a long-term care facility. Gerontologist. 2002 Jun; 42(3):342-349. [PubMed: 12040136]

9. Christakis NA, Lamont EB. Extent and determinants of error in doctors' prognoses in terminally ill patients: prospective cohort study. BMJ. 2000 Feb 19; 320(7233):469-472. [PubMed: 10678857]

10. Huskamp HA, Keating NL, Malin JL, et al. Discussions with physicians about hospice among patients with metastatic lung cancer. Arch Intern Med. 2009 May 25; 169(10):954-962. [PubMed: 19468089]

11. Casarett D, Karlawish J, Morales K, Crowley R, Mirsch T, Asch DA. Improving the use of hospice services in nursing homes: a randomized controlled trial. Jama. 2005 Jul 13; 294(2):211-217. [PubMed: 16014595]

12. Wright AA, Zhang B, Ray A, et al. Associations between end-of-life discussions, patient mental health, medical care near death, and caregiver bereavement adjustment. JAMA. 2008 Oct 8; 300(14):1665-1673. [PubMed: 18840840]

13. Medical guidelines for determining prognosis in selected non-cancer diseases. The National Hospice Organization. Hosp J. 1996; 11(2):47-63. [PubMed: 8949013]

14. Fox E, Landrum-McNiff K, Zhong Z, Dawson NV, Wu AW, Lynn J. Evaluation of prognostic criteria for determining hospice eligibility in patients with advanced lung, heart, or liver disease. SUPPORT Investigators. Study to Understand Prognoses and Preferences for Outcomes and Risks of Treatments. JAMA. 1999 Nov 3; 282(17):1638-1645. [PubMed: 10553790]

15. Huskamp HA, Stevenson DG, Grabowski DC, Brennan E, Keating NL. Long and short hospice stays among nursing home residents at the end of life. J Palliat Med. 2010 Aug; 13(8):957-964. [PubMed: 20666661]

16. Christakis NA, Escarce JJ. Survival of Medicare patients after enrollment in hospice programs. N Engl J Med. 1996 Jul 18; 335(3):172-178. [PubMed: 8657216]

17. Brickner L, Scannell K, Marquet S, Ackerson L. Barriers to hospice care and referrals: survey of physicians' knowledge, attitudes, and perceptions in a health maintenance organization. J Palliat Med. 2004 Jun; 7(3):411-418. [PubMed: 15265350]

18. Kaldjian LC, Erekson ZD, Haberle TH, et al. Code status discussions and goals of care among hospitalised adults. J Med Ethics. 2009 Jun; 35(6):338-342. [PubMed: 19482974]

19. Smith TJ, Dow LA, Virago E, Khatcheressian J, Lyckholm LJ, Matsuyama R. Giving honest information to patients with advanced cancer maintains hope. Oncology (Williston Park). 2010 May; 24(6):521-525. [PubMed: 20568593]

20. Carlson MD, Herrin J, Du Q, et al. Impact of hospice disenrollment on health care use and medicare expenditures for patients with cancer. J Clin Oncol. 2010 Oct 1; 28(28):4371-4375. [PubMed: 20805463]

21. Taylor DH Jr, Ostermann J, Van Houtven CH, Tulsky JA, Steinhauser K. What length of hospice use maximizes reduction in medical expenditures near death in the US Medicare program? Soc Sci Med. 2007 Oct; 65(7):1466-1478. [PubMed: 17600605] 
22. Zhang B, Wright AA, Huskamp HA, et al. Health care costs in the last week of life: associations with end-of-life conversations. Arch Intern Med. 2009 Mar 9; 169(5):480-488. [PubMed: 19273778]

23. Pyenson B, Connor S, Fitch K, Kinzbrunner B. Medicare cost in matched hospice and non-hospice cohorts. J Pain Symptom Manage. 2004 Sep; 28(3):200-210. [PubMed: 15336332]

24. Norton SA, Hogan LA, Holloway RG, Temkin-Greener H, Buckley MJ, Quill TE. Proactive palliative care in the medical intensive care unit: effects on length of stay for selected high-risk patients. Crit Care Med. 2007 Jun; 35(6):1530-1535. [PubMed: 17452930]

25. Teno JM, Shu JE, Casarett D, Spence C, Rhodes R, Connor S. Timing of referral to hospice and quality of care: length of stay and bereaved family members' perceptions of the timing of hospice referral. J Pain Symptom Manage. 2007 Aug; 34(2):120-125. [PubMed: 17583469]

26. Rady MY, Johnson DJ. Admission to intensive care unit at the end-of-life: is it an informed decision? Palliative medicine. 2004 Dec; 18(8):705-711. [PubMed: 15623167]

27. Farnon C, Hofmann M. Factors contributing to late hospice admission and proposals for change. Am J Hosp Palliat Care. 1997 Sep-Oct;14(5):212-218. [PubMed: 9341336]

28. Bell CL, Kuriya M, Fischberg D. Hospice Referrals and Code Status: Outcomes of Inpatient Palliative Care Consultations Among Asian Americans and Pacific Islanders with Cancer. Journal of pain and symptom management. 2011 Apr 22.

29. Fromme EK, Bascom PB, Smith MD, et al. Survival, mortality, and location of death for patients seen by a hospital-based palliative care team. Journal of palliative medicine. 2006 Aug; 9(4):903911. [PubMed: 16910805]

30. Teno JM, Gruneir A, Schwartz Z, Nanda A, Wetle T. Association between advance directives and quality of end-of-life care: a national study. J Am Geriatr Soc. 2007 Feb; 55(2):189-194.

[PubMed: 17302654] 


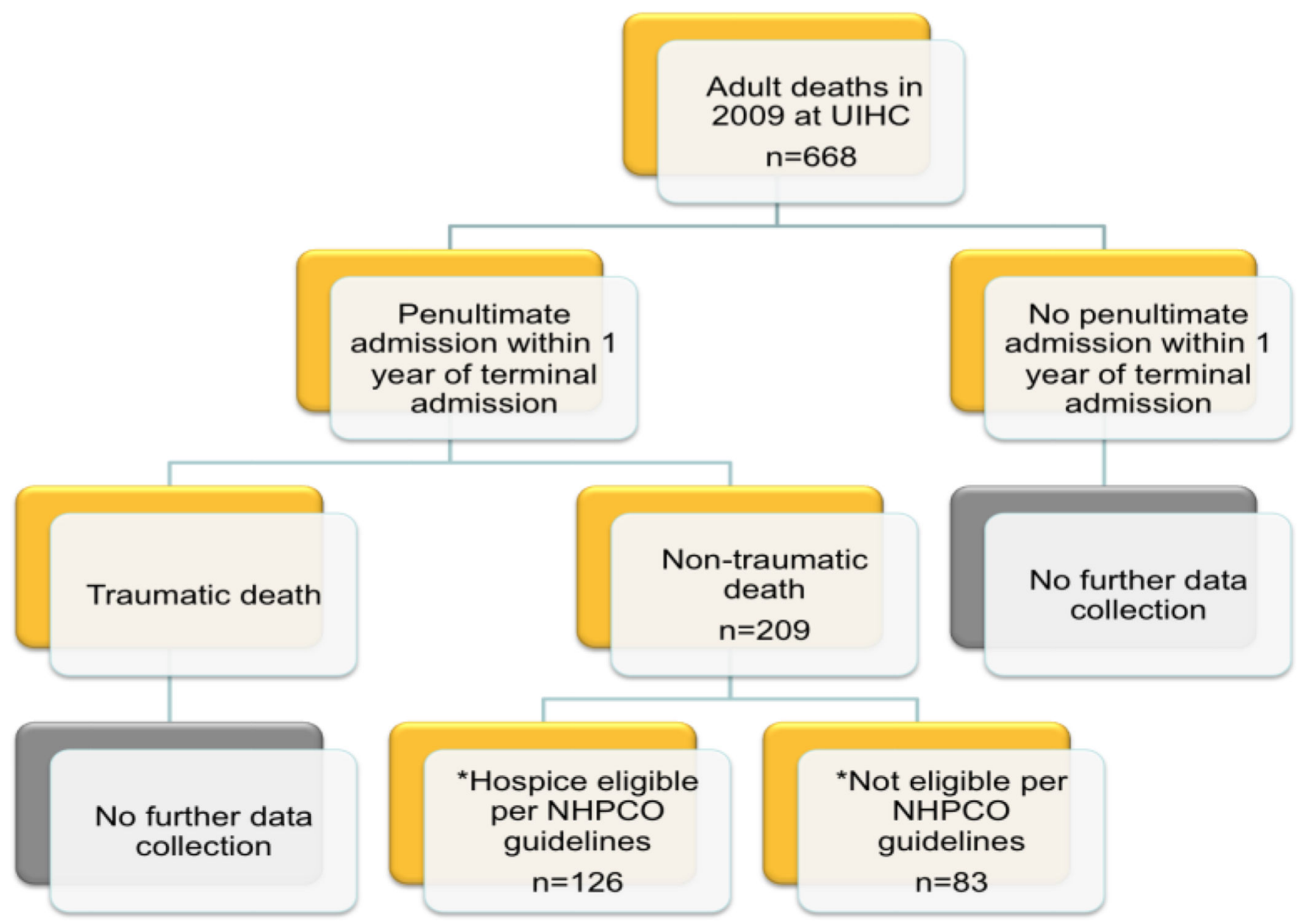

Figure 1.

Study Design 
Table 1

Characteristics of admitting services and frequency of hospice referrals at penultimate admission

\begin{tabular}{|l|l|l|l|}
\hline Admitting services & $\begin{array}{l}\text { Total patients } \\
\mathbf{N = 2 0 9}\end{array}$ & $\begin{array}{l}\text { Hospice eligible } \\
\mathbf{N = 1 2 5}\end{array}$ & $\begin{array}{l}\text { Hospice referral } \\
\text { N=11 }\end{array}$ \\
\hline General medicine or family medicine teaching team & 56 & 34 & 3 \\
\hline General medicine hospitalist & 9 & 3 & 0 \\
\hline Medicine subspecialty service* & & & \\
\hline Cardiology/gastrointestinal/pulmonary & 47 & 26 & 0 \\
\hline Hematology/oncology & 46 & 40 & 5 \\
\hline Intensive Care Unit & 12 & 5 & 2 \\
\hline Surgical service & 33 & 16 & 1 \\
\hline Neurology & 6 & 2 & 0 \\
\hline
\end{tabular}

* All of the pulmonary admission and about half of the cardiology admissions were to a specialty hospitalist and physician extender team. The reminder of the medicine subspecialty services were resident teaching services. 


\section{Table 2}

Sample characteristics during penultimate admission

\begin{tabular}{|c|c|c|c|c|}
\hline \multirow[b]{2}{*}{ Characteristic } & \multirow[b]{2}{*}{$\begin{array}{l}\text { Total Sample } \\
(\mathrm{N}=209)\end{array}$} & \multicolumn{2}{|c|}{ Hospice eligible } & \multirow[b]{2}{*}{$P$ value } \\
\hline & & $\begin{array}{l}\text { Yes } \\
(N=125)\end{array}$ & $\begin{array}{l}\text { No } \\
(\mathrm{N}=84)\end{array}$ & \\
\hline Age, mean (SD), y & & $63.8(16.9)$ & $62.9(14.3)$ & $0.67^{a}$ \\
\hline \multicolumn{5}{|l|}{ Sex, No. $(\%)$} \\
\hline Male & $128(61.2 \%)$ & $70(55 \%)$ & $58(45 \%)$ & 0.06 \\
\hline Female & $81(38.8 \%)$ & $55(68 \%)$ & $26(32 \%)$ & \\
\hline \multicolumn{5}{|l|}{ Race/ethnicity, No. (\%) } \\
\hline White, non-Hispanic & $174(83.3 \%)$ & $107(61.5 \%)$ & $67(38.5 \%)$ & \\
\hline Black, non-Hispanic & $7(3.3 \%)$ & $2(28.6 \%)$ & $5(71.4 \%)$ & \\
\hline Hispanic & $3(1.4 \%)$ & $2(66.7 \%)$ & $1(33.3 \%)$ & 0.49 \\
\hline Asian & $3(1.4 \%)$ & $2(66.7 \%)$ & $1(33.3 \%)$ & \\
\hline Other & $22(10.5 \%)$ & $12(54.5 \%)$ & $10(45.5 \%)$ & \\
\hline Non-white (total) & $35(16.7 \%)$ & $18(51.4 \%)$ & $17(48.6 \%)$ & 0.27 \\
\hline Number of secondary organ systems listed on discharge summary, mean (SD) & & $3.10(1.825)$ & $3.11(1.826)$ & 0.99 \\
\hline Number of subspecialty consults, mean (SD) & & $0.656(1.23)$ & $0.250(0.692)$ & $0.003^{a}$ \\
\hline Number of admissions in the year prior to the terminal admission, mean (SD) & & $3.254(2.86)$ & $1.940(1.83)$ & 0.0003 \\
\hline \multicolumn{5}{|l|}{ Primary discharge diagnosis, No. (\%) } \\
\hline Cancer & $46(22 \%)$ & $35(76.1 \%)$ & $11(23.9 \%)$ & \\
\hline Gastrointestinal & $36(17.2 \%)$ & $22(61.1 \%)$ & $14(38.9 \%)$ & \\
\hline Infection & $33(15.8 \%)$ & $23(69.7 \%)$ & $10(30.3 \%)$ & \\
\hline Cardiac/vascular & $32(15.3 \%)$ & $15(46.9 \%)$ & $17(53.1 \%)$ & \\
\hline Respiratory & $16(7.7 \%)$ & $13(81.2 \%)$ & $3(18.8 \%)$ & $<0.001 b$ \\
\hline Renal & $15(7.2 \%)$ & $9(60 \%)$ & $6(40 \%)$ & \\
\hline Neurological & $13(6.2 \%)$ & $4(30.8 \%)$ & $9(69.2 \%)$ & \\
\hline Hematological & $7(3.3 \%)$ & $4(57.1 \%)$ & $3(42.9 \%)$ & \\
\hline Orthopedic & $6(2.9 \%)$ & 0 & $6(100 \%)$ & \\
\hline Endocrine & $4(1.9 \%)$ & 0 & $4(100 \%)$ & \\
\hline Rheumatological & $1(0.4 \%)$ & 0 & $1(100 \%)$ & \\
\hline \multicolumn{5}{|l|}{ Days between penultimate and terminal admission, No. (\%) } \\
\hline $0-13$ & $13(6.2 \%)$ & $9(7.2 \%)$ & $4(4.8 \%)$ & \\
\hline $14-30$ & $53(25.4 \%)$ & $41(33 \%)$ & $12(14.3 \%)$ & \\
\hline $31-90$ & $77(36.8 \%)$ & $53(42 \%)$ & $24(28.5 \%)$ & $<0.001$ \\
\hline $91-180$ & $32(15.3 \%)$ & $13(10.4 \%)$ & $19(22.6 \%)$ & \\
\hline$>180$ & $34(16.3 \%)$ & $9(7.2 \%)$ & $25(29.8 \%)$ & \\
\hline \multicolumn{5}{|l|}{ Type of Insurance/Payors, No. (\%) } \\
\hline Commercial & $44(21 \%)$ & $30(24 \%)$ & $14(16.7 \%)$ & \\
\hline
\end{tabular}

J Hosp Med. Author manuscript; available in PMC 2016 March 28. 


\begin{tabular}{|l|l|l|l|l|}
\hline & & \multicolumn{2}{l|}{ Hospice eligible } & \\
\hline Characteristic & $\begin{array}{l}\text { Total Sample } \\
(\mathbf{N = 2 0 9})\end{array}$ & $\begin{array}{l}\text { Yes } \\
(\mathbf{N}=\mathbf{1 2 5})\end{array}$ & $\begin{array}{l}\text { No } \\
(\mathbf{N}=\mathbf{8 4})\end{array}$ & P value \\
\hline Medicare/Medicaid/State Aide & $158(75.6 \%)$ & $93(74.4 \%)$ & $65(77.4 \%)$ & $0.05 b$ \\
\hline Military & $4(1.9 \%)$ & 0 & $4(4.8 \%)$ & \\
\hline Other & $3(1.4 \%)$ & $2(1.6 \%)$ & $1(1.2 \%)$ & \\
\hline
\end{tabular}

${ }^{a}: 2$ sample t-test

${ }^{b}$ : Fisher exact test 